Article

\title{
A Cross-National Comparative Policy Analysis of the Blockchain Technology between the USA and China
}

\author{
Chu-Chi Kuo *(1) and Joseph Z. Shyu \\ Institute of Management of Technology, National Yang Ming Chiao Tung University, Hsinchu City 30010, Taiwan; \\ joseph@cc.nctu.edu.tw \\ * Correspondence: joshkuo.mg03@nycu.edu.tw
}

Citation: Kuo, C.-C.; Shyu, J.Z. A Cross-National Comparative Policy Analysis of the Blockchain

Technology between the USA and China. Sustainability 2021, 13, 6893. https://doi.org/10.3390/su13126893

Academic Editor: Roberto Cerchione

Received: 10 March 2021

Accepted: 10 June 2021

Published: 18 June 2021

Publisher's Note: MDPI stays neutral with regard to jurisdictional claims in published maps and institutional affiliations.

Copyright: (c) 2021 by the authors. Licensee MDPI, Basel, Switzerland. This article is an open access article distributed under the terms and conditions of the Creative Commons Attribution (CC BY) license (https:/ / creativecommons.org/licenses/by/ $4.0 /)$.

\begin{abstract}
Blockchain technology can achieve decentralization, multi-party verification, anti-tampering, anonymity, traceability of transactions and distributed ledger applications. Countries around the world continue to seek blockchain business models, technologies and applications and have different visions and policies for the development of blockchain. This study provides a comparative policy framework for the theoretical analysis of blockchain technology between the USA and China. Using the innovative policy tools proposed by Rothwell and Zegveld, these two countries are analyzed from the viewpoint of twelve policy tools. The results show that the USA and China both prefer to use "Environmental-side" policies. The USA has focused more on "Legal and regulatory", "Public services" and "Procurement". China has the highest proportion of policies in "Political tools", followed by "Legal and regulatory", while "Scientific and technical", "Education" and "Overseas agent" come in third. Blockchain technology has developed vigorously among industries and its applications have gradually diversified. The results can provide a reference for policy planning for various stakeholders.
\end{abstract}

Keywords: blockchain; decentralization; innovation policy; national innovation systems; policy tools; legal and regulatory

\section{Introduction}

In 2008, in a paper entitled "Bitcoin: A Peer-to-Peer Electronic Cash System", Nakamoto proposed the concept of electronic currency and the algorithm of bitcoin [1]. Bitcoin was born on 3 January 2009. Unlike other currencies, Bitcoin is generated by an algorithm rather than a specific issuer. It is a decentralized digital currency. Bitcoin achieved great success in the capital market in 2016, reaching a value of USD 10 billion [2]. Bitcoin's overall annual market value soared from USD 20,000 at the end of 2017 to a record high of nearly USD 65,000 in April 2021. According to data from CoinMarketCap, the total market value of Bitcoin escalated from USD 15.6 billion in early 2017 to a record high of USD 1220 billion in April 2021 [3].

The underlying key technology used by Bitcoin is blockchain technology, which is hailed as the disruptive innovation of the 21st century. Schwab, the founder of the World Economic Forum (WEF), predicted that blockchain technology will be the foundation for an industrial revolution [4]. Moreover, blockchain technology will change people's lives and have a significant effect on the global economic structure. According to the research results of Mei and Liu, there were a total of 682 cryptocurrencies based on blockchain technology as of September 2016 [5], of which Bitcoin accounted for 79\% of the total. Concurrently, more than 2500 blockchain-related patents have been issued. Considering the potential value of blockchain, multinational industry giants have developed different areas of blockchain by setting up research groups, investing in blockchain startups, developing blockchainbased platforms and researching future potential applications. Increasing evidence of the potential of cryptocurrencies has also begun to drive a wave of entrepreneurial innovation in blockchain [5]. 
Blockchain was originally a bitcoin-enabling technology, but today it has evolved into a large technology ecosystem and many new organizations related to blockchain have emerged. Financial services can benefit from blockchain technology because it enables the completion of transactions without an intermediary [6,7]. In addition, blockchain technology is one of the unparalleled technologies of next-generation systems, such as Internet of Things (IoT) for E-business [8], public services [9], security services [10], reputation and reward record systems [11] and privacy-preserving smart contracts [12]. For example, the Hyperledger Project was created by the Linux Foundation with the goal of building enterprise-level blockchain technology that can be implemented in every industry and already has hundreds of members including Accenture management consultants, IBM and dozens of banks [13]. Meanwhile, the Enterprise Ethereum Alliance (EEA), created by JPMorgan, Microsoft, Intel and more than 30 companies in 2017, is a member-driven enterprise Ethereum ecosystem that stimulates new businesses and consumers [14]. In 2019, International Association of Trusted Blockchain Applications brought diverse organizations together to help bring Distributed Ledger Technology (DLT) and blockchain into the mainstream across numerous divisions [15].

The scope of the applications of blockchain technology ranges from the financial field (digital currency, bank cross-border payment and remittance, electronic tickets, crowdfunding) to many non-financial applications, including medicine (such as electronic medical records, pharmaceutical development), supply chain (such as logistics tracking, supply chain management), energy (such as energy trading, energy supply and demand management), agriculture (such as food production and sales, food safety resume), digital rights (such as copyright authorization, art product authenticity verification), public management (such as electronic voting, identity verification), etc. In the UK, the government has been studying blockchain technology to encourage city residents to follow the trail of government funds [16]. China has not fallen behind in the applications of blockchain, with industry leaders launching a food blockchain traceability system: OwlChain [17], sports event blockchain system: BraveLog [18] and travel management blockchain system: OwlNest [19], in which a detailed history of athletes' diet and sports information helps hoteliers to manage their reservation systems. In Denmark, Blockchain-enabled e-voting $(\mathrm{BEV})$ has been applied in elections. In Estonia, BEV is utilized in shareholder votes [16]; moreover, the government has examined the use of ID cards with blockchain implemented services. Real estate transactions in Sweden use blockchain to allow parties to track the progress of transactions and ensure authenticity and transparency in the trading process, saving a substantial amount of time and cost [16]. Moreover, blockchain technology has been used for welfare payments in the UK [16].

In recent years, numerous studies have been published that demonstrate the capacity of blockchain technology in many fields and the number of studies has grown exponentially. Centobelli et al. used a bibliometric method to examine the evolution of blockchain technology research [20]. Gorkhali, Li and Shrestha conducted an extensive survey of 76 journal publications from 2016 to 2018 in the blockchain field, available in the Social Science Citation Index and Science Citation Index databases, aiming to provide a detailed overview of the available research resources for academics and practitioners in the blockchain field [21]. This current study conducts a comparative policy framework of theoretical analysis of the blockchain technology and summarizes the differences and ranks between the USA and China. Using the innovative policy framework proposed by Rothwell and Zegveld [22], which is a well-defined framework and most frequently cited working model, the two governments' actions are analyzed from the viewpoint of twelve government policy tools. This paper proceeds with the following sections. In Section 2, we review the related developments of blockchain industrial policies. Innovative policy framework in blockchain is presented in Section 3, while Section 4 presents the research methodology. In Section 5, we discuss the comparison of innovative blockchain industry policies employed by the USA and China. In Section 6, we present the conclusions and practical implications. 


\section{Development of Blockchain Industrial Policies}

There are many explanations for the positive development of an industry or a specific industry link in a particular country. The most traditional argument is that the industry enjoys better comparative interest conditions in that country, such as capital or human factors for national advantages. However, this basic assumption does not take into account the special technology and production differences which may be above and beyond those conditions. Therefore, many economists have proposed a number of theoretical counterexamples and amendments to the traditional assumption. For example, Rothwell and Zegveld summarized the required factors for industrial innovation as shown in Figure 1 [22]. They also stated that countries and enterprises can use policies to change relevant factors and conditions to gain competitive advantage and the resources required by industries will vary in different periods and environments. After further analysis and comparison, Porter found that the new theory of competitive advantage must not only raise the level of competition to the national level, but also must focus on technological progress and innovation [23].

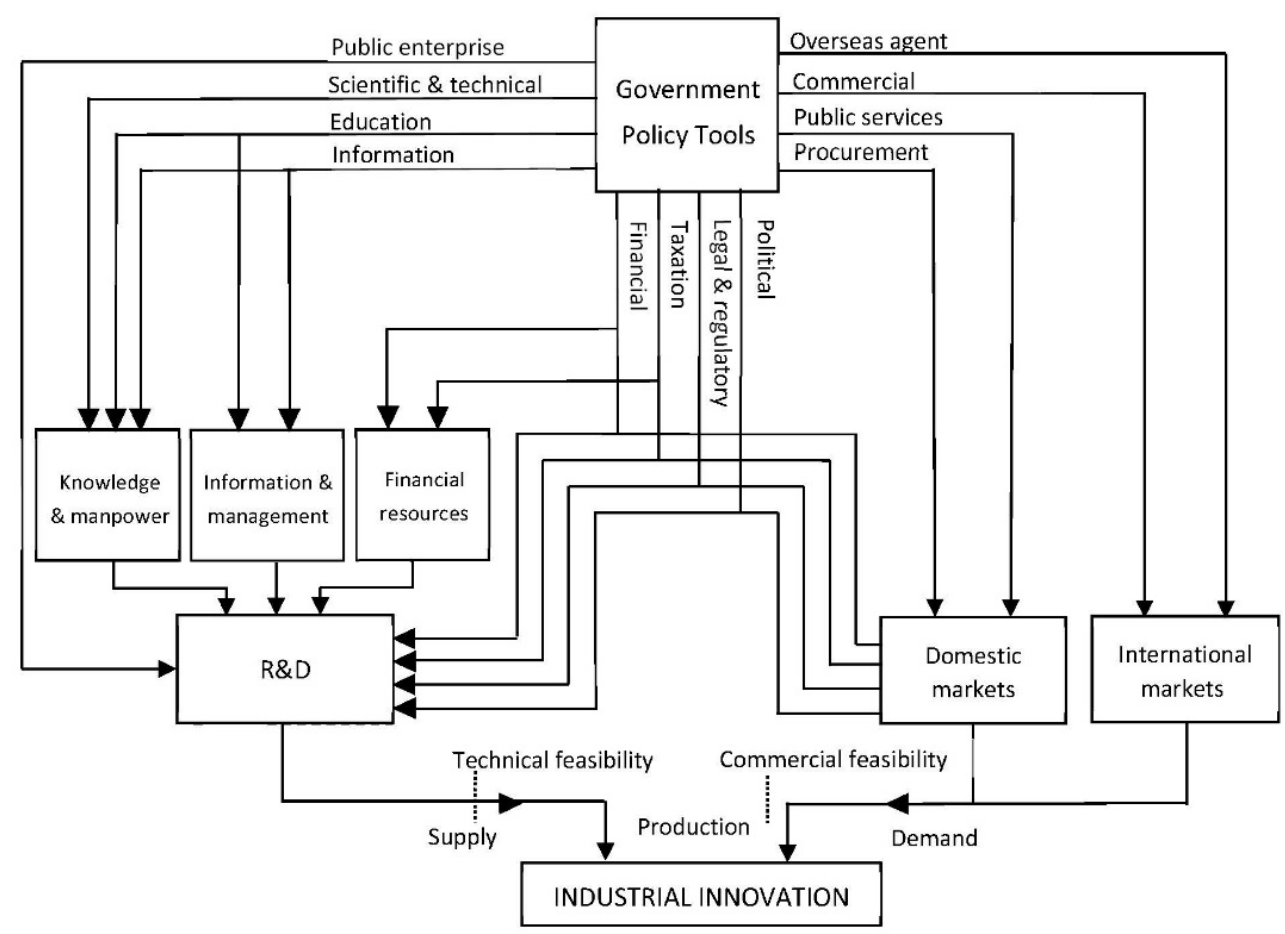

Figure 1. Inducing innovation-required factors for industrial innovation. Source: Rothwell and Zegveld [22].

In the article "Government's role in innovation", Leyden and Link proposed that economic growth is primarily derived from innovative technology [24]. Without intervention by government, enterprises usually have insufficient investment in technology, especially in the arena of basic research. Therefore, government has the responsibility-through rewards or incentives for additional research and development- to address inadequate investment or market failure situations, which will also promote the country's economic growth. Shyu concluded that industries should have different approaches in different development periods and environments; so as to master the key requirements in the process of industrial development, government and industry can make appropriate plans based on industrial requirements [25]. Moreover, innovation infrastructure requires a more detailed analysis and research on the industrial innovation process and structure to find the basic requirements for industrial innovation and development. Porter's argument has clearly shown the importance of industrial technological innovation to a country's competitive advantage [23]. Wang pointed out that national policies, financial systems 
and industrial structures will profoundly affect a country's model of technology learning and innovation [26]. Rothwell and Zegveld explained the impact of industrial innovation, stating that industrial innovation can lead to the growth of a country at all economic levels and the requirements of industry vary in different periods and different environments [22].

Centobelli et al. analyzed the evolution of papers by year between 1985 and 2019 to investigate the degree of blockchain interest among countries and the country ranked first for papers published on this topic was China with 417 papers (20\%), followed by the United States with 325 papers (16\%), then Germany with 129 papers (6\%) [20]. Moreover, there were more than 18,000 applications for blockchain patents globally, in which 35 countries and regions were involved as of 25 July 2019 [27]. China ranks first and the United States ranks second for these applications. Among the top 20 global blockchain agencies filing patent applications, Alibaba Network Technology Co., Ltd. (based out of Hangzhou, China) and China United Network Communications Group Co., Ltd. (Hong Kong-based) respectively ranked first and fifth in the world in terms of applications. Guo stated in "Blockchain Finance Problems and Countermeasures" that blockchain technology is facing imperfect legal systems and high research and development costs and proposed countermeasures for the future development of blockchain finance [28]. Gabison argued that blockchain technology increases expenses to retain records without enough favors, but governments could take measures to propel the aims of openness and justifiability [29]. Mei and Liu introduced the technical principles of blockchain, discussed its industry applications and existing problems and proposed related policy suggestions for government, industry and academic institutions [5]. Novak built a blockchain "crypto-friendliness" model which can evaluate policy accommodation [30].

Appropriate regulatory oversight is an area that deserves due diligence and has been studied in recent years. In 2017, Tencent Research Institute published a white paper on Tencent blockchain solutions, analyzing the globalization trajectory, development pattern and application prospects of blockchain technology [31]; moreover, it published the 2019 Tencent Blockchain White Paper, focusing on industrial blockchain and explaining in detail the breaking of ground for industry blockchains [32]. Huang pointed out that the effective supervision of financial blockchain technology is an issue which has to be resolved earnestly and made risk prevention and regulatory policy recommendations [33]. Truby explored the regulatory, legal and policy aspects related to blockchain technology and digital currencies for sustainable environmental development [34]. Michael et al. investigated blockchain technology regulation in financial services, which faces much regulatory examination as this technology evolves [35]. Allen et al. developed a new model related to innovation policy considering the implications of blockchain innovations [36].

In 2018, European Union (EU) members signed a declaration to cooperate in the establishment of European Blockchain Partnership and European Blockchain Service Infrastructure [37]. The European Commission (EC) stated that blockchain technology could make online transactions highly traceable and secure and is considered a major technological breakthrough $[38,39]$. The aim is for Europe to employ the blockchain economy with a view to gain the leading position of digital technology in the world. Further, the EC issued a proposal on crypto-assets in 2020 [40] to emphasize that blockchain technology needs EU-level expertise and talent [41].

\subsection{The USA's Blockchain Industry Policy}

The United States started to deploy blockchain technology very early and ranks as a leader in blockchain-related patent applications [42]. Although it has always pursued a free-market economy, advocating that the market will be led to the most beneficial outcome for society, the United States has been conservative with regard to cryptocurrencies. The exchanges of Cryptocurrencies and Initial Coin Offerings (ICOs) present regulatory challenges to prevent scam products; thus, a group of market participants launched an agreement on industry standards called Simple Agreement for Future Tokens [43]. The California governor signed a law to secure the legalization of California Bitcoin and other 
digital currency transactions in June 2014 [44]. However, no one was adequately motivated to revoke Section 107 of the California Corporations Code, which states that no corporation, social purpose corporation, association, or individual shall issue or put in circulation, as money, anything but the lawful money of the United States [45]. According to the National Conference of State Legislatures (NCSL), the District of Columbia and Puerto Rico had cryptocurrency legislation on the docket for the 2019 legislative session. Kentucky, Michigan, Colorado, Indiana, Montana, Nevada, Rhode Island, Oregon, Puerto Rico, Tennessee, New York, Texas, Vermont and Wyoming enacted legislation or passed related resolutions that year. [46].

From 2015 to 2017, Circle in Boston, Ripple in San Francisco and Coinbase in New York each received a digital currency license termed BitLicense [47]. The United States can be said to encourage investment and implement strict regulations. In 2017, the United States Securities and Exchange Commission (SEC) determined that the Ethereum token and Decentralized Autonomous Organization (DAO) both belong to the securities issuer and need to register as a securities issue according to law [48,49]. Moreover, the United States Commodity Futures Trading Commission (CFTC) has permitted Derivatives Clearing Organization (DCO) registration to LedgerX, LLC (LedgerX) under the Commodity Exchange Act [50]. In light of the regulatory uncertainty surrounding blockchain technology, the Stanford CodeX Blockchain Group launched the RegTrax initiative with the goal of collecting, tracking and disseminating regulatory developments from around the globe, to create a comprehensive repository of the current formal and developing regulatory landscape, while archiving out-of-date regulations for retrospective analysis [51].

In the 2018 Joint Economic Report issued by the United States Congressional Joint Economic Committee (JEC), comprising an assessment of the United States economy and recommendations for the new year's economic development and blockchain technology is proposed as being a potential tool to assure digital infrastructure in the USA [43]. Since 2014 , there have been two waves of regulatory measures related to cryptocurrencies. In order to avoid the risk of crimes such as money laundering or fraud affecting the development of the industry, the United States government departments focus on maintaining a good competitive order in the market environment and adopting various measures to establish standards. The JEC engaged with Massachusetts Institute of Technology and National Institute of Standards and Technology (NIST) to examine potential encryption standards [43,52]. In addition, many government agencies have cooperated with private enterprises to study the applications of blockchain, including the establishment of a new generation inventory platform to manage and record the health and performance of combatants throughout military operations, as well as supporting patient-level data exchange in United States Critical Illness and Injury Trials Group to improve social welfare applications and to show official attention and support for the blockchain industry [43,52]. Moreover, the U.S. Department of Energy's National Renewable Energy Laboratory, has partnered with BlockCypher to show how blockchain can promote the development of smart grids $[43,53]$.

\subsection{China's Blockchain Industry Policy}

China's national strategic plan, Made in China 2025, clearly states that it is indispensable to increase the innovation, experimentation and implantation of new technologies such as blockchain [54]. China hopes to become the largest economy in the world in the future, have the ability to lead in major international economic and trade organizations and become the leader in regulation. According to statistics, China was the most active country in regard to blockchain patent applications in 2017, with a total of 225 blockchain patents, compared to 91 patents in the United States and 13 patents in Australia [55]. In fact, the major tasks and key projects of the 13th five-year plan issued by the State Council in 2016, indicates that it is essential to reinforce strategic frontier technologies such as blockchain and carry out advanced foundational preparation [56]. Within the Chinese government, the Ministry of Industry and Information Technology (MIIT) and the National 
Standardization Committee worked with a number of well-known companies to compile a China Blockchain Technology and Application Development White Paper in 2016 [57] and then published the China Blockchain Technology and Application Development Research Report in 2018 [58]. The white paper pointed out the core technology path for blockchain and the future direction and process of blockchain technology standardization for China's blockchain-related industry authorities and practitioners.

Mei and Kang pointed out that smart contracts will change the current contract rules and the law [59]. The expression of smart contracts will be very different from that of the parties to a contract under current contract law. Revised contract law must clarify what can be regarded as unanimous expressions of intent, agreement reached and other issues. The September 2017 announcement on Preventing Token Issuance and Financing Risks stipulated that tokens or virtual currencies in token issuance or financing shall not be distributed by the monetary authority, have no monetary attributes such as indemnity and shall not have the same legal status as currency and cannot and should not be used as currency [60]. In terms of education, the China Electronics Technology Standardization Institute of Guangzhou Huangpu District and Guangzhou Development Zone jointly held its second conference of the China Blockchain Technology and Industry Development Forum [57]. During the meeting, supporting policy for blockchain technology was proposed and more application scenarios were provided so that blockchain technology could maximize its value. Moreover, China supports private industry organizations to organize industrial alliances and demonstrates its ambition to become a leader in blockchain industry.

China's current leader, Xi Jinping, first publicly mentioned blockchain at a May 2018 event [61]. His statement can be said to have conveyed the Chinese government's positive signal for blockchain technology. In the China Blockchain Technology and Application Development Research Report (2018), an in-depth analysis of global blockchain applications cases and analysis of the applications scenarios that were relatively mature or had potential application value was presented [58]. Moreover, the China Academy of Information and Communication Technology launched the Blockchain White Paper under the Trusted Blockchain Initiatives plan in 2018 [62] and released the Blockchain White Paper at the end of 2019 [63], which shows China's ambition to actively deploy blockchain and facilitate the development of blockchain industrial innovation.

\section{Innovative Policy Framework in Blockchain}

From the industrial perspective, policies are the tools by which the government intervenes in the realization of the technological development system. Rothwell and Zegveld pointed out that government's innovation policy should comprise both technological and industrial policies $[22,64]$. According to the role of policy in science and technology activities, policy tools fall into three categories: Supply-side policy, Environmental-side policy and Demand-side policy. Furthermore, they categorize government activities into twelve policy tools for industrial innovation and give policy examples of government activities, as shown in Table 1.

In one study, Rothwell and Zegveld indicated that the constitution of technology innovation policies primarily lies in the association of tools among finance, talents and technical support [64]. Secondly, government research on technology contracts and public procurement, respectively, act on the innovation and marketing process and serve as the policy tools for creating demand in domestic and international markets. Moreover, establishing the infrastructure for scientific and technological development, as well as various statutory and incentive measures to encourage academic and corporate efforts in the introduction and dissemination of $\mathrm{R} \& \mathrm{D}$ technologies, are policy tools that establish an innovative environment [65]. 
Table 1. Policy categories, policy tools and examples for industrial innovation.

\begin{tabular}{|c|c|c|}
\hline Policy Categories & Policy Tools & Policy Examples of Government Activities \\
\hline \multirow{4}{*}{ Supply-side } & Public enterprise & $\begin{array}{l}\text { Innovation via publicly owned industries; establishing new industries; } \\
\text { initiating new technologies adoption; taking part in private enterprise. }\end{array}$ \\
\hline & Scientific and technical & $\begin{array}{l}\text { Joining research laboratories for scientific \& technical development; } \\
\text { assisting in research associations, learning societies and professional } \\
\text { associations; grant fellowships in assistance of industrial innovation. }\end{array}$ \\
\hline & Education & $\begin{array}{l}\text { Education and training support at all levels, such as general education, } \\
\text { universities, technical education, apprenticeship schemes, continuing or } \\
\text { further education and retraining. }\end{array}$ \\
\hline & Information service & $\begin{array}{l}\text { Assisting in development of information networks and business centers, } \\
\text { consultancy, advisor, libraries, cloud databases and liaison services. }\end{array}$ \\
\hline \multirow{4}{*}{ Environmental-side } & Financial & $\begin{array}{l}\text { Providing industrial innovation allowance, financial joint investment; } \\
\text { offering loans for equipment, buildings or services, financial loan } \\
\text { guarantee and export credit. }\end{array}$ \\
\hline & Taxation & $\begin{array}{l}\text { Industrial innovation tax exemptions and exemptions for specific } \\
\text { projects; research and development tax credits; indirect taxes and payroll } \\
\text { taxes; and personal allowances. }\end{array}$ \\
\hline & Legal and regulatory & $\begin{array}{l}\text { Patents and intellectual property management; environmental and health } \\
\text { regulatory control; monopoly regulations, supervision of social justice; } \\
\text { certification management; awards, prizes and agreement standards. }\end{array}$ \\
\hline & Political & $\begin{array}{l}\text { Planning national innovation strategy; regional policy; innovation honor } \\
\text { or awards; encouraging joint consortium merger; public consultation on } \\
\text { policy development; legal and political system of investment. }\end{array}$ \\
\hline \multirow{4}{*}{ Demand-side } & Procurement & $\begin{array}{l}\text { Procurements and pacts from government; research \& development } \\
\text { agreements; technological prototype purchases. }\end{array}$ \\
\hline & Public services & $\begin{array}{l}\text { Maintenance, supervision and innovation of health care services, public } \\
\text { buildings, construction, transportation and telecommunications. }\end{array}$ \\
\hline & Commercial & $\begin{array}{l}\text { Currency regulation, tariff, trade agreement, commercial and } \\
\text { commercialization of innovative industries. }\end{array}$ \\
\hline & Overseas agent & $\begin{array}{l}\text { Support innovation and development of international trade } \\
\text { and transactions. }\end{array}$ \\
\hline
\end{tabular}

Source: Rothwell and Zegveld [22].

As many economists have pointed out, successful innovation tracks with appropriate factors from the technology of the supply-side and the market of the demand-side (for example, Freeman [66]). In terms of the supply-side, developing novel products and processes depend on whether there is sufficient investment in the following: (1) knowledge of scientific and technical development and talents; (2) potential market information for innovation and management ability to conduct research, development, production and sales; and (3) financial resources [67]. These three inputs are shown on the left side of Figure 1. It is clear that a government seeking to affect the innovation activities through supply-side policy can do so either through direct participation in the process, or through improving the abovementioned inputs. Or government can reduce intervention by trying to change the broader economic, political and legal environment in which new products are produced. Alternatively, government may improve innovation activities through demandside policy in domestic or international markets. For example, to intervene more directly, a country might act as an overseas sales agent for its national goods.

\section{Materials and Research Methodology}

This research employs the methods of content analysis and statistics to survey and compare the innovative blockchain policies between the USA and China. Weber argues that content analysis uses a set of procedures to elicit effective reasoning from word content [68]. 
Content analysis comprises methodically presenting the blockchain policy tools adopted, while the analysis datasets assist in acquiring superior interpretation of the innovative blockchain policies [69]. The primary properties of blockchain policies are depicted with quantitative explanations derived from descriptive statistics.

First, foundational secondary data is collected from relevant policy texts of the governments of the USA and China, followed by data from relevant reports of research institutions, journals, newspapers and magazines. Relevant industrial technology policies and the latest industry information were downloaded from official government websites and, including that for blockchain technology patents. Since Centobelli et al. pointed out that China and the United States are the top countries for papers published on the blockchain topic [20], this study also takes the blockchain policy texts published from the USA [43] and China [57] as the research objects.

Second, we adopt the classification of twelve government policy tools from Rothwell and Zegveld [22] and convert the blockchain policy texts of the USA and China to derive the government innovation activities matched with Table 1, as this framework is well defined and this working model is the most frequently cited of its kind. According to the classification results of government activities, proportions for each of the twelve policy tools is calculated for the USA and China, respectively.

Third, we not only compare the blockchain policy measures under the three policy categories, but also rank the weights of the policy tools to point out the differences between the USA and China.

When matching innovative blockchain policies to the tools, this research assumes that they all have the same weight even if the activities of policy tools are unlikely to have the same impact. Therefore, this is a research limitation. There are two thoughts behind this assumption. First of all, no quantitative research on cross-national blockchain policy exists; if different weights are assigned to the blockchain policies, it may lead to research bias. Secondly, different countries have different resource conditions, political structures and national conditions; therefore, every policy tool will have divergent weight. Thus, it seems appropriate to the researchers that each policy is given the same weight.

\section{Results}

This study selects the blockchain policy texts published in the 2018 Joint Economic Report [43] and China Blockchain Technology and Application Development White Paper [57], issued, respectively, by the JEC of the United States and MIIT of China, which are promulgated by the highest administrative bodies of these two countries and the best publicly available source of data on working models of relevant policy.

\subsection{The Policy Taxonomy of the USA}

Based on the policy examples of government activities in Table 1, we derive the innovative blockchain policy activities from the 2018 Joint Economic Report. The policy taxonomy results are shown in Table 2, with a total of 23 innovative blockchain policy activities. Furthermore, the proportion for each of the twelve policy tools in the USA is calculated.

\subsection{The Policy Taxonomy of China}

Employing the same method as described in Section 5.1, we derive the innovative blockchain policy activities from China Blockchain Technology and Application Development White Paper. In addition, the policy taxonomy results are shown in Table 3, with a total of 45 innovative blockchain policy activities. Furthermore, the proportion of each of the twelve policy tools in China is calculated. 
Table 2. 2018 Joint Economic Report blockchain policies in the USA.

\begin{tabular}{|c|c|c|c|c|}
\hline Policy Categories & Policy Tools & Policy Activity Description & $Q^{\prime}$ ty & $\%$ \\
\hline Supply-side & Public enterprise & Implement blockchains for private medical data (1). & 1 & 4.3 \\
\hline \multirow{3}{*}{ Environmental-side } & Taxation & Virtual currencies file as money transmitters (1). & 1 & 4.3 \\
\hline & Legal and regulatory & $\begin{array}{l}\text { Regulate and license money transmitters (2); Protect } \\
\text { private property and contract integrity (3); Conduct } \\
\text { regulated research (2); Take actions for securities } \\
\text { registration issues and fraud (1); Work towards } \\
\text { cryptocurrency and blockchain compliance standards (1). }\end{array}$ & 9 & 39.1 \\
\hline & Political & $\begin{array}{c}\text { Blockchain products comply with system and regulators } \\
\text { (1); Virtual currency businesses file as money } \\
\text { transmitters (1). }\end{array}$ & 2 & 8.7 \\
\hline \multirow[b]{2}{*}{ Demand-side } & Procurement & $\begin{array}{l}\text { Blockchain products comply with the current system and } \\
\text { regulators (1); Facilitate a smarter energy grid using } \\
\text { blockchain (2); Develop encryption standards for } \\
\text { medical data protection (1); }\end{array}$ & 4 & 17.4 \\
\hline & Public services & $\begin{array}{l}\text { Issue blockchain guidance documents (1); Form working } \\
\text { groups on securities regulations, taxation (1); Investigate } \\
\text { and define security regulation (1); Use blockchain in } \\
\text { health and research (1); Regulatory agencies coordinate } \\
\text { the need for financial products and transactions (1); } \\
\text { Deter and prosecute fraud and abuse (1). }\end{array}$ & 6 & 26.1 \\
\hline
\end{tabular}

Source: Organized from this research.

\subsection{Cross-National Policy Tools Comparison}

In this subsection, as shown in Table 4, we propose a cross-national comparison of innovative blockchain policy tools between the USA and China, where the blockchain policy measures under the three policy categories are compared. Furthermore, as shown in Table 5, we rank the weights of the policy tools of the USA and China, respectively. Although they may not have the same impact on the development of blockchain innovation policies in the United States and China, all policies are given the same weight. This assumption should be considered as a limitation of the study. Figure 2 shows the comparative scattering diagram of twelve policy tools of the USA and China to highlight the innovative blockchain policy tools applied.

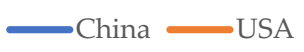

Public enterprise

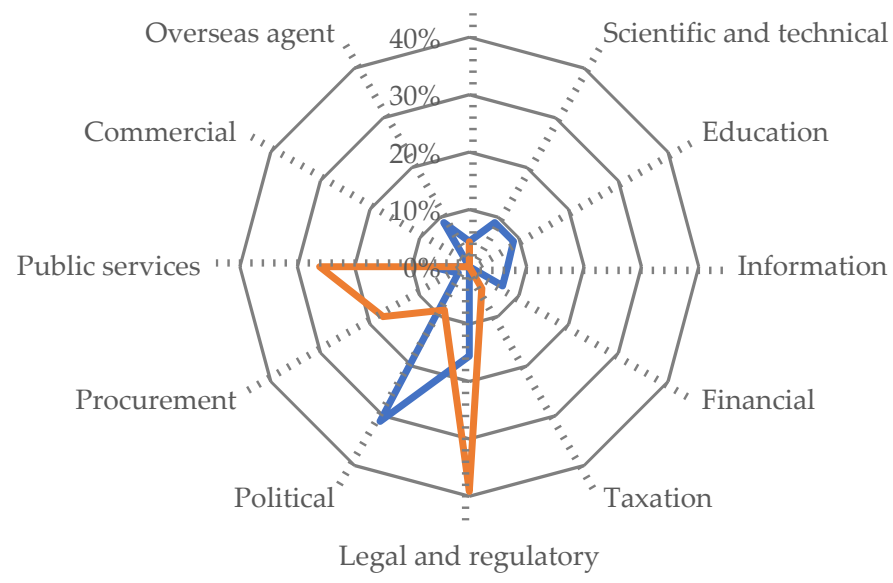

Figure 2. Comparative scattering diagram of twelve policy tools of the USA and China. Source: Organized from this research. 
Table 3. China Blockchain Technology and Applications Development White Paper policies in China.

\begin{tabular}{|c|c|c|c|c|}
\hline Policy Categories & Policy Tools & Policy Activity Description & $Q^{\prime}$ ty & $\%$ \\
\hline \multirow{4}{*}{ Supply-side } & Public enterprise & $\begin{array}{c}\text { Develop blockchain technology and applications (1); } \\
\text { Establish blockchain research working group in financial } \\
\text { sector (1). }\end{array}$ & 2 & 4.4 \\
\hline & Scientific and technicall & $\begin{array}{l}\text { Use information technology to enhance digitalization (1); } \\
\text { Combine blockchain systems and traditional business } \\
\text { models (1); Formulate the requirements for the target system } \\
\text { and the underlying technology platform (2); }\end{array}$ & 4 & 8.9 \\
\hline & Education & $\begin{array}{l}\text { Support key colleges and universities to set up blockchain } \\
\text { professional courses (1); Promote the joint efforts of key } \\
\text { enterprises and universities for blockchain talent training } \\
\text { base (2); Strengthen blockchain professional and technical } \\
\text { personnel for high-end talent training (1). }\end{array}$ & 4 & 8.9 \\
\hline & Information service & $\begin{array}{l}\text { Support demonstration bases and public service platform } \\
\text { construction (2); Build blockchain open source } \\
\text { community (1); }\end{array}$ & 3 & 6.7 \\
\hline \multirow{3}{*}{ Environmental-side } & Financial & $\begin{array}{l}\text { Financial support related to blockchain projects (1); Establish } \\
\text { investment funds (1); Support the development of SMEs (1). }\end{array}$ & 3 & 6.7 \\
\hline & Legal and regulatory & $\begin{array}{l}\text { Guide the formulation of specific standards (5); Standardize } \\
\text { the comprehensive system listed in the framework (1); Relax } \\
\text { market access restrictions (1). }\end{array}$ & 7 & 15.6 \\
\hline & Political & $\begin{array}{c}\text { Promote blockchain technology development and } \\
\text { applications (1); Promote next-generation information } \\
\text { technology (3); Establish blockchain standards system (4); } \\
\text { Accelerate the development of international standards and } \\
\text { reference architectures (3); Build a general development } \\
\text { platform for blockchains (3). }\end{array}$ & 14 & 31.1 \\
\hline \multirow{3}{*}{ Demand-side } & Procurement & $\begin{array}{l}\text { Application standards support for government } \\
\text { procurement (1). }\end{array}$ & 1 & 2.2 \\
\hline & Public services & $\begin{array}{c}\text { Enhance the service to enterprises (1); Promote the scenarios } \\
\text { of commercial, enterprise or financial application (1); Form } \\
\text { blockchain ecology of technical exchanges and cooperation } \\
\text { among enterprises (1). }\end{array}$ & 3 & 6.7 \\
\hline & Overseas agent & $\begin{array}{l}\text { Implement China-US and China-Europe mechanism to } \\
\text { support enterprises (1); Lead/participate in blockchain } \\
\text { international standardization organization (2); Establish } \\
\text { blockchain standards for international community (1). }\end{array}$ & 4 & 8.9 \\
\hline
\end{tabular}


Table 4. Cross-national comparison of the blockchain policy tools between the USA and China.

\begin{tabular}{|c|c|c|c|c|c|}
\hline \multirow{2}{*}{ Policy Categories } & \multirow{2}{*}{ Policy Tools } & \multicolumn{2}{|c|}{ China } & \multicolumn{2}{|c|}{ USA } \\
\hline & & $Q^{\prime}$ ty & $\%$ & $Q^{\prime}$ ty & $\%$ \\
\hline \multirow{5}{*}{ Supply-side } & Public enterprise & 2 & 4.4 & 1 & 4.3 \\
\hline & Scientific and technical & 4 & 8.9 & 0 & 0 \\
\hline & Education & 4 & 8.9 & 0 & 0 \\
\hline & Information service & 3 & 6.7 & 0 & 0 \\
\hline & Sub-total & 13 & 28.9 & 1 & 4.3 \\
\hline \multirow{5}{*}{ Environmental-side } & Financial & 3 & 6.7 & 0 & 0 \\
\hline & Taxation & 0 & 0 & 1 & 4.3 \\
\hline & Legal and regulatory & 7 & 15.6 & 9 & 39.1 \\
\hline & Political & 14 & 31.1 & 2 & 8.7 \\
\hline & Sub-total & 24 & 53.3 & 12 & 52.2 \\
\hline \multirow{5}{*}{ Demand-side } & Procurement & 1 & 2.2 & 4 & 17.4 \\
\hline & Public services & 3 & 6.7 & 6 & 26.1 \\
\hline & Commercial & 0 & 0 & 0 & 0 \\
\hline & Overseas agent & 4 & 8.9 & 0 & 0 \\
\hline & Sub-total & 8 & 17.8 & 10 & 43.5 \\
\hline Total & & 45 & 100 & 23 & 100 \\
\hline
\end{tabular}

Source: Organized from this research.

Table 5. The weighting rank of each policy tool compared between the USA and China.

\begin{tabular}{cccccc}
\hline \multicolumn{2}{c}{ China } & \multicolumn{5}{c}{ USA } \\
\hline Policy Tool & Rank & & Policy Tool & Rank \\
\hline Political & 1 & $31.1 \%$ & Legal and regulatory & 1 & $39.1 \%$ \\
\hline Legal and regulatory & 2 & $15.6 \%$ & Public services & 2 & $26.1 \%$ \\
\hline Scientific and technical & 3 & $8.9 \%$ & Procurement & 3 & $17.4 \%$ \\
\hline Education & 3 & $8.9 \%$ & Political & 4 & $8.7 \%$ \\
\hline Overseas agent & 3 & $8.9 \%$ & Taxation & 5 & $4.4 \%$ \\
\hline Information & 4 & $6.7 \%$ & Public enterprise & 5 & $4.4 \%$ \\
\hline Financial & 4 & $6.7 \%$ & & & \\
\hline Public services & 4 & $6.7 \%$ & & & \\
\hline Public enterprise & 5 & $4.4 \%$ & & & \\
\hline Procurement & 6 & $2.2 \%$ & & & \\
\hline
\end{tabular}

Source: Organized from this research.

\section{Conclusions and Implications}

\subsection{Findings and Discussion}

Based on the policy taxonomy of twelve policy tools from the innovative blockchain policy activities described in white papers from the USA and China as shown in Tables 2 and 3 respectively, this section summarizes the findings of the empirical and comparative analysis as follows.

(1) Under Supply-side policy shown in Table 4, we can see that the Chinese authorities focus more attention than those in the USA. As shown in Table 2, the USA focuses on Public enterprise only and its specific policy activity is to implement blockchain for private medical data with portable and digitally secure ways. Clearly, the USA 
government has realized the potential of blockchain and has begun to implement it for many purposes.

On another point, as shown in Table 3, China attaches great importance to Scientific and technical tools, as well as Education tools. In the former, policy activities include: to formulate the requirements for the target system and the underlying technology platform, use information technology to enhance digitalization and combine blockchain systems and traditional business models. Policy activities under Education promote the joint efforts of key enterprises and universities as training bases for blockchain talents, support key colleges and universities to set up blockchain professional courses and strengthen the blockchain professional and technical personnel for high-end talent training.

(2) Results in Environmental-side policy in Table 4 show that both governments place over $50 \%$ of their attention on this category. As shown in Table 2, the USA authorities tend to emphasize Legal and regulatory tools with the policy activities to regulate and license money transmitters, protect private property and contract integrity, conduct regulated research, take actions for securities registration issues and fraud and work towards cryptocurrencies and blockchains compliance standards such as NIST and HHS. In terms of Political policy activities, these comprise blockchain products complying with systems and regulators and for virtual currency businesses to file as money transmitters. Due to cryptocurrencies, ICOs and their exchanges face new regulatory challenges, resulting in new product cases for legislation to prevent violating the current regulatory framework in the USA.

On the other hand, as shown in Table 3, China is more inclined toward Political tools than Legal and regulatory in Environmental-side policy and is developing a number of potential policy activities to support their program. Under Political tools, the policy activities are to promote next-generation information technology, establish blockchain standards system, accelerate the development of international standards and reference architectures, build a general development platform for blockchains and promote blockchain technology development and applications. In terms of Legal and regulatory tools, China's policy activities are to guide the formulation of specific standards, standardize the comprehensive system listed in the framework and relax market access restrictions. China authorities actively implement the State Council's Deepening Standardization Work Reform Plan, give priority to blockchain technology and industrial development forums, formulate and promote group standards and simultaneously promote international standardization, as China expects to become the world's largest economic system in the future.

(3) In Demand-side policy, Table 4 shows that the USA authorities focus much more attention than those in China. As shown in Table 2, the USA tends to use Public services tools with policy activities to issue blockchain guidance documents, form working groups on securities regulation and taxation, investigate and define security regulation, use blockchain in health and research, coordinate the need for financial products and transactions through regulatory agencies and deter and prosecute fraud and abuse. In terms of Procurement, the policy activities include blockchain products complying with the current system and regulators, facilitation of a smarter energy grid with blockchain and development of encryption standards for medical data protection. The CFTC, SEC, federal and state regulators and criminal justice authorities work together to bring transparency and integrity to deter and prosecute fraud and abuse.

In contrast, as shown in Table 3, China values Overseas agent tools more, with policy activities to lead and participate in international standardization organizations, with China-US and China-Europe mechanism to support enterprises and establish blockchain standards for the international community. In terms of Public services, China's policy activities are to enhance services to enterprises, promote the scenarios of commercial, enterprise or financial applications and form blockchain ecology of technical exchanges and cooperation among enterprises. 
(4) In the USA, $52.1 \%$ of the innovative blockchain policy activities of the 2018 Joint Economic Report fall under Environmental-side policy category, as shown in Table 4, where the main policy tool is Legal and regulatory at $39.1 \%$. Second, $43.5 \%$ of all policy tools are found in the Demand-side policy category and where most of the resources are allocated to Public services, at $26.1 \%$ and Procurement, at $17.4 \%$. Finally, there is the Supply-side policy category with only $4.3 \%$ of activities, with Public enterprise as the only group of policy tools. Therefore, Legal and regulatory is seen to be the most important policy tool in the USA as shown in Table 5, followed by Public services, while Procurement ranks third. Since Legal and regulatory and Political are both in Environmental-side policy category, this category becomes the most important aspect of the USA government approach to blockchain. This analysis shows that the USA ignores the Scientific and technical, Education, Information service, Financial, Commercial and "Overseas agent" policy tools. It can be seen that in terms of policy, the USA focuses on maintaining a good market competition order and adopts measures to establish standards and create a good competitive environment under Environmental-side policy. On the Demand-side policy, through the provision of public services, blockchain technology can enjoy a friendly space. In addition, in which to develop. Finally, the very limited Supply-side policy is in line with the laissez-faire market principle of the USA.

The top three policy tools in the USA, Legal and regulatory, Public services and Procurement, account for more than $80 \%$ of innovative blockchain policy activities, as shown in Table 5. Legal and regulatory policy tools can strengthen the domestic market in the process of industrial innovation and development as shown in Figure 1, thereby promoting the R\&D activities of the sector. Public services and Procurement policy tools can be inferred to enhance the domestic market in the process of industrial innovation and development as shown in Figure 1. In December 2019, a briefing on the use of blockchain technology for defense purposes, accompanying the National Defense Authorization Act for FY2020 that passed into law, introduced the potential use of DLT for national defense purposes to the National Defense Committee of the U.S. Congress. The brief included an explanation of how the Department of Defense (DoD) may use DLT, i.e., (1) through distributed computing and centralized computing, improve the network security of vulnerable assets such as energy, water and transportation grids from the hardware level; (2) reduce single points of failure in emergency and catastrophic decisions by making decisions through DLT for consensus verification; (3) improve the efficiency of national defense logistics and supply chain operations; (4) improve the transparency of procurement audits; (5) allow the private sector to adjust innovations for auxiliary purposes [70,71]. Moreover, according to NSCL, twenty states handled cryptocurrency legislation in their 2020 legislative sessions, such as Wyoming modified the instrument to complete a security interest in virtual currency and digital securities, New York set up a digital currency task force, Arizona established the Blockchain and Cryptocurrency Research Committee and Louisiana created licensure demands for virtual currency businesses [72].

(5) In China, as shown in Table 4, the innovative blockchain policy activities laid out in the China Blockchain Technology and Application Development White Paper allocate most of the resources to Environmental-side policy category, at $53.3 \%$, followed by Supply-side policy category with $28.9 \%$ and then Demand-side policy category with $17.8 \%$. Of all the policy tools, Political tools account for the highest proportion, at $31.1 \%$, as shown in Table 5, followed by Legal and regulatory with $15.6 \%$, while Scientific and technical, Education and Overseas agency ranked third, each with $8.9 \%$. It is found that China neglects the Taxation and Commercial policy tools. In terms of policy, it can be seen that China urgently needs to establish technical standards in the face of as-yet immature blockchain technology in industry. At the same time, China's Political policy tools support private enterprises to organize industrial alliances, unite internal forces and demonstrate China's ambition to become a leader in blockchain technology. 
In China, a high proportion of Political, as well as Legal and regulatory policy tools are adopted to develop the blockchain industry and they can be inferred to strengthen the domestic market in the process of industrial innovation and development, as shown in Figure 1, thereby promoting the R\&D activities of the sector. Moreover, Scientific and technical and Education tools of Supply-side policy and Overseas agent of Demand-side policy all rank third in the weightings of the twelve policy tools for China and. These can be inferred not only to strengthen technical knowledge and manpower in the sector, but also to enhance market information and management skills, thereby improving R\&D activities in the process of industrial innovation and development as shown in Figure 1, while Overseas agent policy tools can strengthen industry's international markets in the process of industry innovation and development. To actively grasp the historical opportunities of blockchain development, jointly create and maintain a good industrial development environment and continue to promote the development of blockchain technology and industry, the China Blockchain Technology and Application Development Research Report (2018) summarized the development of blockchain technology, its applications and standardization since 2016, when the original blockchain white paper was issued. Not only did the 2018 report propose methods for application scenario selection, application governance and application evaluation, it also provided a number of typical domestic application cases [58]. Blockchain has entered a period of rapid development in China, but in this process, problems such as high chain-building costs, heterogeneous underlying platforms, inability to interact with data and difficulty in application promotion all hinder the large-scale application of blockchain. Thus, China officially released a nationwide blockchain service network (BSN), or blockchain hosting platform, in 2019, jointly initiated by the State Information Center, China Mobile Communications Corporation, and a payroll services company called Red Date (all Beijing-based), along with Shanghai-based China UnionPay Co., Ltd. This BSN is committed to solving the abovementioned problems, taking advantage of cloud service infrastructure and providing developers with a public area of the blockchain resource environment based on the Internet concept, which greatly reduces the cost of development, deployment, operation and maintenance, intercommunication and supervision of blockchain applications. Thereby, rapid popularization and development of blockchain technology is enabled with the prospect of developing China's future blockchain infrastructure and expanding the market to strive for setting international standards [73].

\subsection{Conclusions}

Centobelli et al. used a bibliometric method based on performance and network analysis techniques for the analysis of centrality and density measurement and identifying six major clusters of blockchain-related research contributions to provide pivotal insight for policy makers and practitioners [20]. Gorkhali, Li and Shrestha grouped the selected papers in the blockchain field into 14 categories, summarized the contents of papers in each category and outlined future research directions for each category, indicating that the research on blockchain is shifting more and more and, so further efforts are needed to develop novel methodologies and frameworks to conform blockchain operations [21]. Building on that foundation, this current study employs an analysis framework of national innovation systems, combined with relevant literatures and methods and discussed at the national level, which uses the methods of content analysis and statistics to survey and compare the innovative blockchain policies between the USA and China. The innovative blockchain policies adopted by the USA and China are derived from government-issued white papers to present blockchain policy measures under the three policy categories by means of the policy analytical framework of Rothwell and Zegveld [22]. Based on the statistical results of the weighting rank of each policy tool compared between the USA and China shown in Table 5, the USA is seen to pay more attention to Legal and regulatory and Public services tools, while China has a higher proportion of policy tools in Political, Legal and regulatory and Education arenas. Due to the different political and economic 
environments, there are corresponding blockchain policy differences, but both the USA and China mention the important oversight of Legal and regulatory policy. Although blockchain technology can create tremendous value and solve problems that could not be solved in the past in areas such as finance, public welfare, supervision and fraud, this technology has a significant impact on the traditional legal system and; thus, its emergence has spawned many legal issues.

Novak's research found inclination toward beneficial policy regarding blockchain technology is expressed as political efforts to evolve local, blockchain-enabled economies [30]. Policy makers in countries/regions that oppose blockchain-related activity have imposed prohibitions or strict restrictions on developers and users participating in blockchain activities. Thus, how to construct the standards for blockchain technology so that blockchain technology can maximize its value is also a problem that urgently needs to be solved. Therefore, how countries and can appropriately face the complex challenges of legislation and regulation posed by blockchain technology, while encouraging technological innovation, is a future research direction.

\subsection{Practical Implications}

This research investigates how governments may practically develop and formulate innovative blockchain policies and provides useful guidance to industry. Moreover, this comparative research on cross-national blockchain policies also provides useful policy portfolio design guidelines for developed and developing countries. Since private companies do not have advanced technical support to create the innovative systems required for blockchain, it is very important to use Demand-side policies to formulate guidance along the path of industrial development in developing countries. On the contrary, Environmental-side policy may need to be emphasized in advanced economies and developed countries, where the government should fully establish blockchain service facilities and infrastructure, guide development of blockchain regulations and develop key blockchain technologies and manpower training. These results provide practical illustrations for policy formulation leading to blockchain industry development. It should be noted that the USA and China are countries with larger blockchain cases, not only are their domestic resources abundant, but their market demand is great. Thus, for small countries or newly industrialized economies that are oriented towards export policies, these cross-national research results and findings may not be applicable.

Moreover, in industrial development of blockchain, each activity of blockchain policy may not have the same effect. However, all policy tools are given the same weight in this study as the development of government blockchain policy activity in any country is currently insufficient to accurately calculate varied effects at this stage. This is a limitation of the research study. It is recommended that a cross-national study on this issue be carried out in the future. Because of this limit, these research results may not be readily extended to all areas of industry and may be subject to the influence of complementary interpretations [74]. Relying on the authors' blockchain knowledge and industrial application skills, the quality of this research is also easily affected by the researchers' personal views and characteristics.

Supplementary Materials: The following are available online at https:/ /www.mdpi.com/article/10 $.3390 /$ su13126893/s1.

Author Contributions: Conceptualization, C.-C.K. and J.Z.S.; methodology, C.-C.K. and J.Z.S.; validation, C.-C.K.; formal analysis, C.-C.K. and J.Z.S.; investigation, C.-C.K.; resources, C.-C.K. and J.Z.S.; data curation, C.-C.K.; writing-original draft preparation, C.-C.K.; writing-review and editing, J.Z.S.; visualization, C.-C.K.; supervision, J.Z.S.; project administration, C.-C.K. All authors have read and agreed to the published version of the manuscript.

Funding: This research received no external funding.

Institutional Review Board Statement: Not applicable.

Informed Consent Statement: Not applicable. 
Data Availability Statement: The data presented in this study are available in Supplementary Materials.

Conflicts of Interest: The authors declare no conflict of interest.

\section{References}

1. Nakamoto, S. Bitcoin: A Peer-to-Peer Electronic Cash System. Available online: https://bitcoin.org/bitcoin.pdf (accessed on 25 March 2020).

2. State of Blockchain q1 2016: Blockchain Funding Overtakes Bitcoin. Available online: http://www.coindesk.com/state-ofblockchain-q1-2016/ (accessed on 1 April 2020).

3. Global Charts: Bitcoin Market Capitalization. Available online: https://coinmarketcap.com/currencies/bitcoin/ (accessed on 22 April 2021).

4. Schwab, K. The Fourth Industrial Revolution: Currency; Crown Business: New York, NY, USA, 2017.

5. Haitao, M.E.I.; IUJie, L. Industry present situation, existing problems and strategy suggestion of blockchain. Telecom. Sci. 2016, 32, 134-138. [CrossRef]

6. Foroglou, G.; Tsilidou, A.L. Further applications of the blockchain. In Proceeding of the 12th Student Conference on Managerial Science and Technology, Athens, Greece, 14 May 2015; pp. 1-8.

7. Peters, G.; Panayi, E.; Chapelle, A. Trends in cryptocurrencies and blockchain technologies: A monetary theory and regulation perspective. SSRN J. 2015, 3. [CrossRef]

8. Zhang, Y.; Wen, J. An IoT electric business model based on the protocol of bitcoin. In Proceedings of the 201518 th International Conference on Intelligence in Next Generation Networks, Paris, France, 17-19 February 2015; pp. 184-191. [CrossRef]

9. Akins, B.W.; Chapman, J.L.; Gordon, J.M. A whole new world: Income tax considerations of the Bitcoin economy. Pittsbg. Tax Rev. 2014, 12, 25. [CrossRef]

10. Noyes, C. Bitav: Fast anti-malware by distributed blockchain consensus and feedforward scanning. arXiv 2016, arXiv:1601.01405.

11. Sharples, M.; Domingue, J. The blockchain and kudos: A distributed system for educational record, reputation and reward, In Proceeding of the European Conference on Technology Enhanced Learning. Lyon, France, 13-16 September 2016; pp. 490-496.

12. Kosba, A.; Miller, A.; Shi, E.; Wen, Z.; Papamanthou, C. Hawk: The blockchain model of cryptography and privacy-preserving smart contracts. In Proceedings of the 2016 IEEE Symposium on Security and Privacy (SP), San Jose, CA, USA, 22-26 May 2016; pp. 839-858.

13. Dhillon, V.; Metcalf, D.; Hooper, M. The hyperledger project. In Blockchain Enabled Applications; Apress: Berkeley, CA, USA, 2017; pp. 139-149.

14. Enterprise Ethereum Alliance, About the EEA. Available online: https:/ / entethalliance.org/ (accessed on 25 March 2020).

15. Launch of the International Association of Trusted Blockchain Applications-INATBA. Available online: https://ec.europa. eu/digital-single-market/en/news/launch-international-association-trusted-blockchain-applications-inatba (accessed on 28 October 2019).

16. Boucher, P. How blockchain technology could change our lives: In-depth analysis. Eur. Parliam. Res. Serv. 2017, 6-24. [CrossRef]

17. An Open Blockchain Platform, OwlChain. Available online: https://www.owlting.com/owlchain/?l=en (accessed on 25 March 2020).

18. Blockchain-Based Athletic Data Registry for Serious Athletes, BraveLog. Available online: https://bravelog.tw/ (accessed on 25 March 2020).

19. Blockchain Hotel Management Service, OwlNest. Available online: https://www.owlting.com/owlnest?l=tw (accessed on 25 March 2020).

20. Centobelli, P.; Cerchione, R.; Esposito, E.; Oropallo, E. Surfing blockchain wave, or drowning? Shaping the future of distributed ledgers and decentralized technologies. Technol. Forecast. Soc. Chang. 2021, 165, 120463. [CrossRef]

21. Gorkhali, A.; Li, L.; Shrestha, A. Blockchain: A literature review. J. Manag. Anal. 2020, 7, 321-343. [CrossRef]

22. Rothwell, R.; Zegveld, W. Industrial Innovation and Public Policy: Preparing for the 1980s and the 1990; Praeger: Santa Barbara, CA, USA, 1981.

23. Porter, M.E. Competitive Advantage of Nations: Creating and Sustaining Superior Performance; The Free Press: New York, NY, USA, 1990.

24. Leyden, D.P.; Link, A.N. Government's Role in Innovation; Kluwer: Norwell, MA, USA, 1992.

25. Shyu, J.Z. Global Technology Policy and Business Operations; Hwa Tai Publishing: Taipei, Taiwan, 1999.

26. Wang, J.H. From technological catch-up to innovation-based economic growth: South Korea and Taiwan compared. J. Dev. Stud. 2007, 43, 1084-1104. [CrossRef]

27. Xu, D.; Zhang, Y.; Zhang, D.; Zhang, D.; Wang, X.; Cai, Y. Development trend and application analysis of blockchain with 5G. Telecommun. Sci. 2020, 36, 117-124.

28. Guo, Y. Problems and countermeasures in blockchain finance. Friends Account. 2017, 19, $63-67$.

29. Gabison, G. Policy considerations for the blockchain technology public and private applications. SMU Sci. Technol. Law Rev. 2016, 19, 327.

30. Novak, M. Crypto-friendliness: Understanding blockchain public policy. J. Entrepreneurship Public Policy 2019, 9, 165-184. [CrossRef]

31. Tencent Research Institute. White Paper on Blockchain Solutions: Building the Foundation of Trust in the Era of Digital Economy. Available online: https://www.hellobtc.com/d/file/201910/cd91a680d806ce1d7ac665b90f43bc04.pdf (accessed on 28 October 2019). 
32. 2019 Tencent Blockchain White Paper. Tencent Research Institute. Available online: https://www.hellobtc.com/kp/du/10 /tengxunqukuailian.html (accessed on 25 March 2020).

33. Huang, R. Research on the supervision of financial blockchain technology. Acad. Forum 2016, 38, 53-59.

34. Truby, J. Decarbonizing Bitcoin: Law and policy choices for reducing the energy consumption of Blockchain technologies and digital currencies. Energy Res. Soc. Sci. 2018, 44, 399-410. [CrossRef]

35. Rennock, M.J.W.; Cohn, A.; Butcher, J.R. Blockchain Technology and Regulatory Investigations. Pract. Law Litig. 2018, 2 , 35-44.

36. Allen, D.W.; Berg, C.; Markey-Towler, B.; Novak, M.; Potts, J. Blockchain and the evolution of institutional technologies: Implications for innovation policy. Res. Policy 2020, 49, 103865. [CrossRef]

37. European Blockchain Services Infrastructure. Available online: https:/ / ec.europa.eu/cefdigital/wiki/display/CEFDIGITAL/ EBSI\#: \{\}:text=European\%20Blockchain\%20Partnership\%20declaration, and\%20maturity\%20of\%20today \T1 $\backslash$ textquoterights\% 20society (accessed on 5 October 2019).

38. European Commission. Blockchain Technologies, Shaping Europe's Digital Future. Available online: https://ec.europa.eu/ digital-single-market/en/blockchain-technologies (accessed on 23 September 2020).

39. The EU Blockchain Observatory and Forum, European Commission. Available online: http://europa.eu/rapid/press-release_IP18-521_en.htm (accessed on 5 October 2019).

40. European Commission. Proposal for a REGULATION OF THE EUROPEAN PARLIAMENT AND OF THE COUNCIL on Markets in Crypto-Assets, and Amending Directive (EU) 2019/1937. Available online: https:/ / ec.europa.eu/transparency/regdoc/rep/ 1/2020/EN/COM-2020-593-F1-EN-MAIN-PART-1.PDF (accessed on 12 December 2020).

41. Committee on Economic and Monetary Affairs, European Parliament. Report on Virtual Currencies. Available online: https: / / www.europarl.europa.eu/doceo/document/A-8-2016-0168_EN.pdf?redirect (accessed on 12 December 2020).

42. Chiu, M.J.; Clarivate. Blockchain Technology Patents Mainly Layout Market. Available online: https://clarivate.com.tw/blog/20 17/08/30/blockchain-technology-patent/ (accessed on 25 March 2020).

43. Report of the Joint Economic Committee, Congress of the United States. The 2018 Joint Economic Report. Available online: https:/ / www.congress.gov/115/crpt/hrpt596/CRPT-115hrpt596.pdf (accessed on 28 March 2019).

44. Musil, S.; California Governor Signs Bill Legalizing Bitcoin, Other Digital Currencies. A New Law Reverses Prohibition against Use of Anything but US Currency for Commerce. Available online: https://www.cnet.com/news/california-governor-signs-billlegalizing-bitcoin-other-digital-currencies / (accessed on 5 October 2019).

45. Section 107, CORPORATIONS CODE. California Legislative Information. Available online: https: / /leginfo.legislature.ca.gov / faces/codes_displaySection.xhtml?lawCode=CORP\&sectionNum=107 (accessed on 21 April 2021).

46. Cryptocurrency 2019 Legislation, National Conference of State Legislatures (NSCL). Available online: https://www.ncsl.org/ research/financial-services-and-commerce/cryptocurrency-2019-legislation.aspx (accessed on 24 April 2021).

47. Castillo, M. Bitcoin Exchange Coinbase Receives New York BitLicense. Available online: https://www.coindesk.com/bitcoinexchange-coinbase-receives-bitlicense (accessed on 2 January 2020).

48. Aaron, S. The Trump Administration is Buying Into Blockchain Tech. Available online: https://www.coindesk.com/the-trumpadministration-is-buying-into-blockchain-tech (accessed on 5 October 2019).

49. Falkon, S. The Story of the DAO-Its History and Consequences. Available online: https://medium.com/swlh/the-story-of-thedao-its-history-and-consequences-71e6a8a551ee (accessed on 5 October 2019).

50. US Commodity Futures Trading Commission. CFTC Grants DCO Registration to LedgerX LLC. Available online: https: / / www.cftc.gov / PressRoom/PressReleases / pr7592-17 (accessed on 5 October 2019).

51. Stanford CodeX Blockchain Group. 61 RegTrax Initiative. Available online: https://law.stanford.edu/codex-the-stanford-centerfor-legal-informatics/about-regtrax/ (accessed on 12 December 2020).

52. The Joint Economic Committee, United States Congress. Blockchain's Medical Potential. Available online: https://www.jec. senate.gov/public/index.cfm/republicans/2017/8/blockchain-s-medical-potential (accessed on 22 April 2021).

53. BlockCypher and U.S. Department of Energy's National Renewable Energy Laboratory. To Provide Blockchain Agnostic Distributed Energy Solution. Available online: http:/ / www.prweb.com/releases/2018/01/prweb15117801.htm (accessed on 21 April 2021).

54. Made in China 2025, Key Technology Roadmap (2015 Edition). Available online: http:/ /www.cae.cn/cae/html/files/2015-10/29 /20151029105822561730637.pdf (accessed on 5 October 2019).

55. Lu, E.Y. Blockchain Patent: China Ranked First in Blockchain Patent Applications in 2017. Available online: https://www. blocktempo.com/china-filed-the-most-blockchain-patents-in-2017 (accessed on 2 January 2020).

56. The State Council of the People's Republic of China. Notice of the 13th Five-Year National Informationization Plan. Available online: http:/ / www.gov.cn/zhengce/content/2016-12/27/content_5153411.htm (accessed on 5 October 2019).

57. China Blockchain Technology and Industry Development Forum, Department of Information Technology and Software Services, Ministry of Industry and Information Technology. China Blockchain Technology and Applications Development White Paper. 2016. Available online: http:/ /www.cbdforum.cn/bcweb/index/article/rsr-6.html (accessed on 28 March 2019).

58. Ministry of Industry and Information Technology Information Center. China Blockchain Technology and Applications Development White Paper. 2018. Available online: http:/ /www.miit.gov.cn/n1146290/n1146402/n1146445/c6180238/part/6180297.pdf (accessed on 28 October 2019). 
59. Mei, Z.; Kang, Y. The Application of BlockChain Technology in Financial Industry and Legal Consideration. J. Shanghai Lixin Univ. Account. Financ. 2017, 4, 41-50.

60. The Announcement on Preventing Token Issuance and Financing Risks. Available online: https://www.financialnews.com.cn/ jg/dt/201709/t20170904_123977.html (accessed on 12 December 2020).

61. Gao, J.Y.; Business Next. Talking about Blockchain for the First Time, Xi Jinping: Innovation Is Always a Life of Nine Deaths. 31 May 2018. Available online: https:/ / www.bnext.com.tw/article/49328/president-of-china-endorses-blockchain-technology (accessed on 2 January 2020).

62. China Academy of Information and Communications. Blockchain White Paper. 2018. Available online: http://www.caict.ac.cn/ kxyj/qwfb/bps/201809/P020180905517892312190.pdf (accessed on 5 October 2019).

63. China Academy of Information and Communications. Blockchain White Paper. 2019. Available online: http://www.caict.ac.cn/ kxyj/qwfb/bps/201911/P020191108365460712077.pdf (accessed on 8 November 2019).

64. Rothwell, R.; Zegveld, W. An assessment of government innovation policies. Rev. Policy Res. 1984, 3, 436-444. [CrossRef]

65. Rothwell, R.; Dodgson, M. Innovation and size of firm. In The Handbook of Industrial Innovation; Edward Elgar: Aldershot, UK, 1994; pp. 310-324.

66. Freeman, C. The determinants of innovation: Market demand, technology, and the response to social problems. Futures 1979, 11, 206-215. [CrossRef]

67. Allen, T.J.; Utterback, J.M.; Sirbu, M.A.; Ashford, N.A.; Hollomon, J.H. Government influence on the process of innovation in Europe and Japan. Res. Policy 1978, 7, 124-149. [CrossRef]

68. Weber, R.P. Basic Content Analysis; Sage: Newburt Park, CA, USA, 1990.

69. Yin, R.K. Case Study Research: Design and Methods; Sage: Thousand Oaks, CA, USA, 2009.

70. Briefing on the Use of Blockchain Technology for Defense Purposes: The Conference Report Accompanying the National Defense Authorization Act for FY2020. Available online: https://docs.house.gov/billsthisweek/20191209/CRPT-116hrpt333.pdf (accessed on 22 April 2021).

71. POTENTIAL USES OF BLOCKCHAIN BY THE U.S. DEPARTMENT OF DEFENSE. Value Technology Foundation. Available online: https:/ / www.crowell.com/files/Potential-Uses-of-Blockchain-Technology-In-DoD.pdf (accessed on 22 April 2021).

72. National Conference of State Legislatures (NSCL). Cryptocurrency 2020 Legislation. Available online: https://www.ncsl.org/ research/financial-services-and-commerce/cryptocurrency-2020-legislation.aspx (accessed on 24 April 2021).

73. Comprehensive Interpretation "New Infrastructure" of China Development and Reform Commission-Blockchain Service Network (BSN). Available online: https://www.blocktempo.com/introduction-of-chinas-blockchain-service-network/ (accessed on 21 April 2021).

74. Creswell, J.W.; Creswell, J.D. Research Design: Qualitative, Quantitative, and Mixed Methods Approaches; Sage Publications: Thousand Oaks, CA, USA, 2017. 